\title{
INTERAÇÃO ENTRE TRANSGÊNICOS (BT) E INSETICIDAS NO CONTROLE DE PRAGAS-CHAVE EM HÍBRIDOS DE MILHO-SAFRINHA
}

\author{
M.D. Michelotto ${ }^{1}$, E.L. Finoto ${ }^{1}$, A.L.M. Martins ${ }^{1}$, A.P. Duarte ${ }^{2}$ \\ 1Polo Apta do Centro Norte, CP 24, CEP15830-000, Pindorama, SP, Brasil. E-mail: michelotto@apta.sp.gov.br
}

\author{
RESUMO
}

\begin{abstract}
A cultura do milho é atacada por diversos lepidópteros-praga. Recentemente, foi liberada no Brasil a comercialização de híbridos de milho Bt, integrando em seu genoma o gene Cry1Ab, proveniente de Bacillus thuringiensis subsp. kurstaki, que codifica a proteína com efeito tóxico sobre insetos da ordem Lepidooptera. Dessa forma, o objetivo deste trabalho foi avaliar, em condições de campo, a eficácia de híbridos de milho convencionais e transgênicos para o controle de pragas, submetidos ou não à pulverização com inseticidas. O ensaio foi realizado em área experimental do Polo Apta Centro Norte, em Pindorama, Estado de São Paulo. Foram avaliados cinco híbridos de milho convencionais em comparação com os respectivos híbridos isogênicos $B t$. A avaliação dos danos visuais de Spodoptera frugiperda (Smith) foi realizada a cada 10 dias, em 20 plantas das duas linhas centrais da parcela, e para Helicoverpa zea (Bod.) e Diatraea saccharalis (Fab.) na pré-colheita. As interações entre os híbridos e a transgenia ocorreram em todas as avaliações a partir dos 40 dia após emergência (DAE). Os híbridos transgênicos (Bt) avaliados apresentaram as menores notas de danos visuais de $S$. frugiperda em todas as avaliações. A transgenia também proporcionou menor percentagem de espigas danificadas por $H$. zea e $S$. frugiperda e de colmos atacados por $D$. saccharalis. Conclui-se que a transgenia proporciona redução nos danos visuais ocasionados pelas pragas, embora apresente desempenho diferente entre os híbridos.
\end{abstract}

PALAVRAS-CHAVE: Zea mays, Spodoptera frugiperda, Diatraea saccharalis, Bacillus thuringiensis, híbrido transgênico.

\begin{abstract}
INTERACTION BETWEEN TRANSGENICS AND INSECTICIDES IN THE CONTROL OF KEY PESTS ON OFF-SEASON MAIZE HYBRIDS. Diverse lepidopteran pests attack the maize crop. The commercialization of hybrids of transgenic $B t$ maize, integrating in its genome the gene Cry $1 \mathrm{Ab}$, from Bacillus thuringiensis subsp. kurstaki, which codifies the protein with toxic effect on insects of the Lepidoptera order, has been recently introduced in Brazil. The objective of this work was to evaluate, under field conditions, the effectiveness of conventional and transgenic maize hybrids for the control of pests, sprayed or not with insecticides. The assay was carried out in an experimental area of the Polo Apta Centro Norte, in Pindorama, São Paulo State, Brazil. Five conventional maize hybrids were evaluated in comparison with the respective isogenic Bt hybrids. The evaluation was carried out every 10 days, in 20 plants of the 2 central lines of the parcel for Spodoptera frugiperda (Smith) damage. For damages of Helicoverpa zea (Bod.) and Diatraea saccharalis (Fab.) the evaluations were carried out in the pre-harvest. The interactions between the hybrids and the transgeny occurred in all evaluations starting at the 40th day after emergence (DAE). The Bt hybrids evaluated presented the lowest scores for visual $S$. frugiperda damages in all the evaluations. The transgenic maize also provided the lowest percentage of cobs damaged by H. zea and S. frugiperda, and of stalks attacked by $D$. saccharalis. In conclusion, the transgenic maize provided reduction in visual damages caused by the pests, however, it presented different performance among the hybrids.
\end{abstract}

KEY WORDS: Zea mays, Spodoptera frugiperda, Diatraea saccharalis, Bacillus thuringiensis, transgenic maize.

\section{INTRODUÇÃO}

O milho safrinha é conduzido sem irrigação e em sucessão ao cultivo de primavera-verão, repre- sentando uma alternativa econômica de uso da terra em períodos após o da safra normal. Além disso, possibilita a obtenção de melhores preços devido a menor oferta do produto nessa época (PICANÇo et al., 2004).

${ }^{2}$ Polo Apta do Médio Paranapanema, Assis, São Paulo, Brasil. 
No Estado deSão Paulo, o milho safrinha ocupou uma área de aproximadamente 270 mil hectares na safra de 2009 com produtividade média de 3.345 kg.ha-1 ${ }^{-1}$ (CONAB, 2009).

Um dos principais fatores que comprometem o rendimento e a qualidade da produção desta cultura é a incidência de pragas. Dentre estas, destacam-se os lepidópteros lagarta-do-cartucho, Spodoptera frugiperda (Smith), a lagarta-da-espiga, Helicoverpa zea (Bod.) e a brocadacana-de-açúcar, Diatraea saccharalis (Fab.) (Duarte et al., 2007; Gallo et al., 2002).

Pesquisas sobre a ocorrência de insetos-praga e seus inimigos naturais no milho safrinha no Brasil mostraram que este é atacado pelas mesmas pragas da safra de verão, porém as pragas podem mudar de "status". Isto é, pragas que são secundárias na safra de verão passam a se constituir pragas-chave no milho safrinha e vice-versa. Também tem-se verificado, geralmente, maior severidade de danos de insetos-praga na safrinha do que no cultivo de verão (GASSEN, 1999; CRUZ; BiAnCo, 2001).

A lagarta-do-cartucho, quando em condições favoráveis, aumenta sua população, destruindo folhas e cartuchos e comprometendo a produção de grãos (Pencoe; Martin, 1981). No Brasil, as perdas variam de 17 a 38,7\% (CARVALHO, 1970; CRUZ; TuRPIN, 1982; Carnevalli; Florcovski, 1995; Cruz et al., 1999). Segundo CRUz et al. (1999), as perdas estimadas em função das infestações de $S$. frugiperda, no Brasil, são da ordem de 400 milhões de dólares por ano.

Com o advento da biotecnologia, foi desenvolvida uma nova tática de controle de pragas, que consistenas plantas geneticamentemodificadas resistentesainsetos. Através de apuradas técnicas de laboratório, um gene deBacillus thuringiensis Berliner (Bt) foi introduzidoem plantas de milho, dando origem ao milho geneticamente modificado, conferindo alto padrão de resistência da planta a algumas espécies delepidópteros-praga (ARMSTRONG et al., 1995). O gene introduzido codifica a expressão de proteínas $B t$, com ação inseticida, efetivas no controle de lepidópteros como $S$. frugiperda ( $\mathrm{LYNCH}$ et al., 1999; BARRY et al., 2000; BUNTIN et al., 2001; HUANG et al., 2002). As lagartas, ao se alimentarem do tecido foliar do milho geneticamente modificado, ingerem essa proteína, que atua nas células epiteliais do tubo digestivo dos insetos. A proteína promove a ruptura osmótica dessas células, determinando a morte dos insetos, antes que eles consigam causar danos à cultura (Gill et al., 1992; Pietrantonio et al., 1993; Gill, 1995; MEYERs et al., 1997).

A tecnologia do milho geneticamente modificado foi lançada comercialmente nos EUA, em 1996, e vem sendo utilizada também em outros países, como Canadá, Argentina, África do Sul, Espanha e França. Nesses países, o milho geneticamente modificado resistente a lepidópteros-praga foi plantado em 8,3 milhões de hectares, representando $18 \%$ da área cultivada com culturas geneticamente modificadas (JAMES, 2000).

No Brasil, a liberação comercial de híbridos de milho geneticamente modificados só foi autorizada recentemente. Por isso, poucas são as informações relacionadas às condições nacionais e há a necessidade de estudos em condições de campo para avaliar a eficácia da tecnologia comparada a híbridos comerciais não $B t$ e aplicação de inseticidas para o controle da lagarta-do-cartucho.

\section{MATERIAL E MÉTODOS}

O experimento foi realizado na safrinha de 2008 emárea experimental do Polo Apta Centro Norte, em Pindorama, SP e instalado de acordo com as normas recomendadas pela CTNBio. Cabe ressaltar que os materiais usados neste ensaio foram liberados para comercialização em 2007 pela própria CTNBio.

\section{Instalação do ensaio}

O delineamento experimental utilizado foi inteiramente casualizado, em esquema fatorial $5 \times 2 \times 2$, totalizando 20 tratamentos, com quatro repetições cada. O primeiro fator correspondeu aos cinco híbridos comerciais (AG7000, AG9010, DKB330, DKB350 e DKB390). Esses híbridos foram selecionados em função de já existir os híbridos isogênicos nos quais foi introgredido o gene derivado do $B$. thuringiensis, o qual confere resistência a certas espécies de lepidópteros-praga são eles: AG7000YG, AG9010YG, DKB330YG, DKB350YG e DKB390YG. As sementes dos híbridos de milho, convencional e geneticamente modificado, foram fornecidas pelas empresas produtoras dos materiais. Osegundofator foi constituído pela utilização da transgenia ou não (híbridos transgênicos e híbridos convencionais) e o último fator pela pulverização ou não com inseticidas, sendo estas aplicações de acordo com a necessidade.

Cada parcela foi constituída de seis linhas de $20 \mathrm{~m}$ sendoconsideradas áreas úteis somente a duas linhas centrais, para evitar a migração de lagartas de outras parcelas. A semeadura foi realizada com semeadora tratorizada de acordo com as recomendações para cada híbrido. A adubação de semeadura consistiu de 350 kg.ha-1 do produto formulado NPK (8-28-16). A adubação de cobertura consistiu de $270 \mathrm{~kg} \cdot \mathrm{ha}^{-1}$ do produto formulado NPK (20-05-20). Os demais tratos culturais foram realizados de acordo com as necessidades da cultura, em sistema de plantio direto e utilizando irrigação suplementar.

As parcelas pulverizadas receberam aplicações de inseticidas aos 10 DAE (Deltaphos $-300 \mathrm{~mL} \cdot \mathrm{ha}^{-1}$ ), aos 30 DAE (Karate Zeon 50 CS - 150 mL.ha- $^{-1}$ ) e aos 60 DAE (Deltaphos EC - 300 mL.ha-1). 


\section{Parâmetros avaliados}

Para a avaliação dos danos ocasionados pela lagarta-do-cartucho, foi realizada a cada 10 dias amostragem ao acaso de 20 plantas por parcela e, por meio de uma escala de notas visuais, atribuiram-se notas que variaram de 0 (sem dano) a 9 (cartucho totalmente destruído) de acordo com FERNANDES et al. (2003), adaptada de DAvis et al. (1992), para verificar a intensidade dos danos foliares. Estas avaliações foram realizadas até o início do pendoamento das plantas.

No períodoqueantecedeu a colheita (pré-colheita) foram avaliados os danos ocasionados pela broca da cana, através da contagem do número de furos presentes no colmo do milho em 10 plantas tomadas ao acaso na parcela. Nas plantas em que ocorreram tais furos, foi avaliado o comprimento $(\mathrm{mm})$ da galeria realizada pelo inseto.

Para avaliar os danos decorrentes das lagartas na espiga, foram amostradas, ao acaso, 10 espigas por parcela. Foi avaliado o número de espigas com danos da lagarta (ponta e base da espiga) e calculou-se a percentagem de espigas com lesão em cada local.

Para atender as necessidades de normalidade e homocedasticidade, antes de proceder a análise, os dados referentes às notas de sintomas foram submetidos à transformação de $(x+0,5)^{1 / 2}$ e os dados de percentagens submetidos à transformação $\operatorname{arcsen}[(x$
+5)/100] $]^{1 / 2}$. A análise de variância e a comparação de médias pelo teste de Tukey a 5\% de probabilidade, para cada parâmetro avaliado, foram realizadas utilizando o programa estatístico Estat (FCAV/Unesp).

\section{RESULTADOS E DISCUSSÃO}

Na primeira, segunda e terceira avaliação não foi observada diferença significativa para as notas atribuídas aos sintomas visuais de danos da lagartado-cartucho entre os híbridos avaliados (Tabela 1), principalmente pelo fato das sementes possuírem tratamento com inseticidas.

Analisando os híbridos isoladamente, ou seja, sem considerar a transgenia ou a pulverização, observou-se queAG7000 eDKB330foramos materiaisqueapresentaramas maiores notas desintomas visuais. Já o melhor material foiDKB350. Analisando somentea transgenia, observou-se que, a partir da segunda avaliação, os sintomasforam maisintensosnosmateriais convencionais em detrimento dos materiais transgênicos. Resultados semelhantes foram observados nos Estados Unidos por Williams et al. (1997), Buntin et al. (2001) e no Brasil por FERNANDES et al. (2003). O efeito do inseticida só foi avaliado a partir dos 40 dias após emergência (DAE) e todos os materiais não pulverizados foram mais suscetíveis ao ataque da lagarta (Tabela 1).

Tabela 1 - Notas médias atribuídas aos sintomas de ataque da lagarta-do-cartucho nas folhas das plantas e estatística do teste para interações de diferentes híbridos de milho convencionais e transgênicos $(B t)$ submetidos ou não às pulverizações com inseticidas na safrinha. Pindorama, SP, 2008.

\begin{tabular}{|c|c|c|c|c|c|c|c|c|}
\hline \multirow{2}{*}{ Híbridos $(\mathrm{H})$} & \multicolumn{8}{|c|}{ Dias após a emergência das plantas ${ }^{1}$} \\
\hline & 10 & 20 & 30 & 40 & 50 & 60 & 70 & 80 \\
\hline DKB 330 & $0,63 \mathrm{a}$ & $1,24 \mathrm{a}$ & $3,04 \mathrm{a}$ & $2,91 \mathrm{~b}$ & $2,64 \quad b$ & $3,91 \mathrm{~b}$ & $4,10 \mathrm{~b}$ & $4,10 \quad \mathrm{c}$ \\
\hline AG 9010 & $0,51 \mathrm{a}$ & $0,97 \mathrm{a}$ & $2,51 \mathrm{a}$ & $2,09 \mathrm{a}$ & 2,46 a & $3,15 \mathrm{ab}$ & $3,56 \mathrm{~b}$ & $3,14 \quad b$ \\
\hline DKB 390 & $0,53 \mathrm{a}$ & $1,28 \mathrm{a}$ & $2,84 \mathrm{a}$ & $1,94 \mathrm{a}$ & $2,33 \mathrm{a}$ & $2,74 \mathrm{a}$ & $2,68 \mathrm{a}$ & $2,44 \mathrm{ab}$ \\
\hline DKB 350 & $0,56 \mathrm{a}$ & $1,44 \mathrm{a}$ & $2,75 \mathrm{a}$ & $1,89 \mathrm{a}$ & $2,72 \mathrm{a}$ & 2,86 a & $2,66 \mathrm{a}$ & $2,30 \mathrm{a}$ \\
\hline AG 7000 & $0,49 \mathrm{a}$ & $1,17 \mathrm{a}$ & $2,37 \mathrm{a}$ & $2,33 \mathrm{ab}$ & $3,12 \mathrm{ab}$ & $3,21 \mathrm{ab}$ & $3,55 \mathrm{~b}$ & $4,13 \quad \mathrm{C}$ \\
\hline Teste F & $0,84^{\mathrm{ns}}$ & $1,25^{\mathrm{ns}}$ & $0,82^{\mathrm{ns}}$ & $4,17^{* *}$ & $6,44^{* *}$ & 5,59 ** & $12,23^{* *}$ & $19,88^{* *}$ \\
\hline \multicolumn{9}{|l|}{ Transgenia $(\mathrm{T})$} \\
\hline Convencional & $0,57 \mathrm{a}$ & $1,60 \mathrm{~b}$ & $3,95 \mathrm{~b}$ & $3,26 \mathrm{~b}$ & $4,24 \mathrm{~b}$ & $4,67 \mathrm{~b}$ & $4,87 \mathrm{~b}$ & $4,66 \mathrm{~b}$ \\
\hline Transgênico $(B t)$ & $0,52 \mathrm{a}$ & $0,83 \mathrm{a}$ & $1,46 \mathrm{a}$ & $1,21 \mathrm{a}$ & $1,47 \mathrm{a}$ & $1,68 \mathrm{a}$ & $1,76 \mathrm{a}$ & $1,79 \mathrm{a}$ \\
\hline Teste F & $0,61^{\text {ns }}$ & $31,70^{* *}$ & $88,02^{* *}$ & $127,88^{* *}$ & $214,55^{* *}$ & $298,91^{* *}$ & $374,94^{* *}$ & $268,12^{* *}$ \\
\hline \multicolumn{9}{|l|}{ Inseticida (I) } \\
\hline Não Pulverizado & -2 & - & - & $2,77 \mathrm{~b}$ & $3,95 \mathrm{~b}$ & $4,53 \mathrm{~b}$ & $4,15 \mathrm{~b}$ & $3,94 \mathrm{~b}$ \\
\hline Pulverizado & - & - & - & $1,69 \mathrm{a}$ & $1,76 \mathrm{a}$ & $1,81 \mathrm{a}$ & $2,47 \mathrm{a}$ & $2,51 \mathrm{a}$ \\
\hline Teste F & - & - & - & $35,61^{* *}$ & 134,90 ** & $247,77^{* *}$ & $109,81^{* *}$ & $66,56^{* *}$ \\
\hline \multicolumn{9}{|l|}{ Interação } \\
\hline Teste $\mathrm{F}(\mathrm{H} \times \mathrm{T})$ & $2,21^{\text {ns }}$ & $0,48^{\mathrm{ns}}$ & $0,84^{\mathrm{ns}}$ & $2,69 *$ & $3,43^{*}$ & $7,97^{* *}$ & $9,01^{* *}$ & $7,46^{* *}$ \\
\hline $\mathrm{F}(\mathrm{H} \times \mathrm{I})$ & - & - & - & $2,82^{*}$ & 1,68 & 1,05 & $4,45^{* *}$ & $6,00^{* *}$ \\
\hline $\mathrm{F}(\mathrm{T} \times \mathrm{I})$ & - & - & - & $26,43^{* *}$ & $20,88^{* *}$ & $45,84^{* *}$ & $27,25^{* *}$ & $14,67^{* *}$ \\
\hline $\mathrm{F}(\mathrm{H} \times \mathrm{T} \times \mathrm{I})$ & - & - & - & $1,29^{\mathrm{ns}}$ & $1,77^{\mathrm{ns}}$ & $0,62^{\mathrm{ns}}$ & $1,61^{\mathrm{ns}}$ & $1,52^{\mathrm{ns}}$ \\
\hline CV (\%) & 31,7 & 35,4 & 31,0 & 36,4 & 29,6 & 24,4 & 21,7 & 24,4 \\
\hline
\end{tabular}

${ }^{1}$ Médias seguidas de mesma letra na coluna não diferem significativamente entre si pelo teste de Tukey a 5\% de probabilidade de erro.

${ }^{2}$ Não analisado em função de não ter ocorrido a pulverização até essa data de avaliação. 
As interações entre os híbridos e a transgenia ocorreram em todas a partir dos $40 \mathrm{DAE}$ (Tabela 1). Os híbridos transgênicos (Bt) avaliados apresentaram as menores notas visuais em todas as avaliações (Tabela 2). Quando analisado somente os híbridos convencionais, observou-se uma diferença significativa entre os sintomas de danos visuais, na qual os melhores híbridos nas avaliações foram DKB 350 e DKB 390, principalmente a partir dos $60 \mathrm{DAE}$, quando os sintomas foram mais intensos (Tabela 2).
Para os híbridos transgênicos, também foram observadas diferenças significativas aos $80 \mathrm{DAE}$, na qual o híbrido commenor nota de sintoma foi DKB390 com nota igual a 1,09 e o híbrido DKB 330 com maior nota, 2,25 (Tabela 2). Em trabalho realizado nos Estados Unidos por WAQUIL et al. (2002), avaliando diferentes híbridos e eventos (Cry 1Ab, Cry 1Ac, Cry 1F e Cry 9C), foram observadas diferenças significativas para os danos foliares, com materiais variando de nota 0,1 (Híbrido 2722 IMI - Cry 1F) a 8,8 (Híbridos Max 454R176 - Cry 1Ac e Garst 8539 - Cry 9C).

Tabela 2 - Valores da análise de desdobramentos das interações significativas para os sintomas de danos visuais da lagarta-do-cartucho em híbridos de milho convencionais e transgênicos (Bt). Pindorama, SP, 2008

\begin{tabular}{|c|c|c|c|}
\hline \multirow{3}{*}{ Híbridos $(\mathrm{H})$} & \multicolumn{2}{|c|}{ Transgenia (T) } & \multirow{3}{*}{ Teste F } \\
\hline & \multicolumn{2}{|c|}{ Notas de sintomas aos $40 \mathrm{DAE}^{1}$} & \\
\hline & Convencional & Transgênico & \\
\hline DKB 330 & $4,44 \quad \mathrm{~B} \mathrm{~b}$ & $1,38 \mathrm{~A} \quad \mathrm{a}$ & $57,10^{\star *}$ \\
\hline AG 9010 & $3,00 \mathrm{~A} \quad \mathrm{~b}$ & $1,18 \mathrm{~A}$ a & $20,20^{* *}$ \\
\hline DKB 390 & $2,68 \mathrm{~A} \quad \mathrm{~b}$ & $1,11 \mathrm{~A} \quad \mathrm{a}$ & $15,04^{\star *}$ \\
\hline DKB 350 & $2,66 \mathrm{~A} \quad \mathrm{~b}$ & $1,22 \mathrm{~A} \quad \mathrm{a}$ & $12,64^{* *}$ \\
\hline AG 7000 & $3,51 \quad \mathrm{~B} \mathrm{~b}$ & $1,15 \mathrm{~A} \quad \mathrm{a}$ & $33,66^{* *}$ \\
\hline Teste F & $6,74^{* *}$ & $0,13^{\text {ns }}$ & \\
\hline \multirow{2}{*}{ Híbridos $(\mathrm{H})$} & \multicolumn{2}{|c|}{ Notas de sintomas aos $50 \mathrm{DAE}^{1}$} & \multirow{2}{*}{ Teste F } \\
\hline & Convencional & Transgênico & \\
\hline DKB 330 & $5,50 \quad \mathrm{C} \mathrm{b}$ & $1,79 \mathrm{~A} \quad \mathrm{a}$ & $77,36^{\star *}$ \\
\hline AG 9010 & $3,83 \mathrm{AB} \quad \mathrm{b}$ & $1,08 \mathrm{~A} \quad \mathrm{a}$ & $42,45^{\star *}$ \\
\hline DKB 390 & $3,19 \mathrm{~A} \quad \mathrm{~b}$ & $1,46 \mathrm{~A} \quad \mathrm{a}$ & $16,94^{* *}$ \\
\hline DKB 350 & $3,88 \mathrm{AB} \quad \mathrm{b}$ & $1,56 \mathrm{~A} \quad \mathrm{a}$ & $30,18^{* *}$ \\
\hline AG 7000 & $4,77 \quad \mathrm{BC}$ b & $1,46 \mathrm{~A} \quad \mathrm{a}$ & $61,35^{* *}$ \\
\hline Teste F & $9,14^{\star *}$ & $0,73^{\mathrm{ns}}$ & \\
\hline \multirow{2}{*}{ Híbridos $(\mathrm{H})$} & \multicolumn{2}{|c|}{ Notas de sintomas aos $60 \mathrm{DAE}^{1}$} & \multirow{2}{*}{ Teste F } \\
\hline & Convencional & Transgênico & \\
\hline DKB 330 & $6,23 \quad c \quad b$ & $1,59 \mathrm{~A} \quad \mathrm{a}$ & $143,66^{* *}$ \\
\hline AG 9010 & $4,71 \quad$ B $\quad b$ & $1,60 \mathrm{~A} \quad \mathrm{a}$ & $64,63^{* *}$ \\
\hline DKB 390 & $3,61 \mathrm{~A} \quad \mathrm{~b}$ & $1,87 \mathrm{~A} \quad \mathrm{a}$ & $20,22 * *$ \\
\hline DKB 350 & $4,01 \mathrm{AB} \quad \mathrm{b}$ & $1,70 \mathrm{~A} \quad \mathrm{a}$ & $35,82^{* *}$ \\
\hline AG 7000 & $4,79 \quad$ B $\quad$ b & $1,64 \mathrm{~A} \quad \mathrm{a}$ & $66,46^{* *}$ \\
\hline Teste F & 13,39 ** & $0,17^{\mathrm{ns}}$ & \\
\hline \multirow{2}{*}{ Híbridos $(\mathrm{H})$} & \multicolumn{2}{|c|}{ Notas de sintomas aos $70 \mathrm{DAE}^{1}$} & \multirow{2}{*}{ Teste F } \\
\hline & Convencional & Transgênico & \\
\hline DKB 330 & $6,31 \quad \mathrm{D} \quad \mathrm{b}$ & $1,89 \mathrm{~A} \quad \mathrm{a}$ & $151,26^{* *}$ \\
\hline AG 9010 & $5,13 \quad$ BC $\quad$ b & $2,00 \mathrm{~A} \quad \mathrm{a}$ & $75,65^{* *}$ \\
\hline DKB 390 & $4,16 \mathrm{AB} \quad \mathrm{b}$ & $1,19 \mathrm{~A} \quad \mathrm{a}$ & $67,99 * *$ \\
\hline DKB 350 & $3,39 \mathrm{~A}$ & $1,93 \mathrm{~A} \quad \mathrm{a}$ & $16,71^{* *}$ \\
\hline AG 7000 & $5,34 \quad \mathrm{CD} b$ & $1,76 \mathrm{~A} \quad \mathrm{a}$ & $99,36^{* *}$ \\
\hline Teste F & $19,60^{* *}$ & $1,64^{\mathrm{ns}}$ & \\
\hline \multirow{2}{*}{ Híbridos $(\mathrm{H})$} & \multicolumn{2}{|c|}{ Notas de sintomas aos $80 \mathrm{DAE}^{1}$} & \multirow{2}{*}{ Teste F } \\
\hline & Convencional & Transgênico & \\
\hline DKB 330 & $\begin{array}{lll}5,96 & \mathrm{C} & \mathrm{b}\end{array}$ & $2,25 \quad$ B $\quad$ a & $89,12^{* *}$ \\
\hline AG 9010 & $4,49 \quad$ B $\quad$ b & $1,79 \mathrm{AB}$ a & $47,51^{* *}$ \\
\hline DKB 390 & $3,79 \mathrm{AB}$ & $1,09 \mathrm{~A} \quad \mathrm{a}$ & $47,51^{* *}$ \\
\hline DKB 350 & $2,93 \mathrm{~A}$ & $1,67 \mathrm{AB}$ a & $10,34^{* *}$ \\
\hline AG 7000 & $6,13 \quad C \quad b$ & $2,13 \mathrm{AB} \quad \mathrm{a}$ & $103,48^{* *}$ \\
\hline Teste F & $24,63^{* *}$ & $2,71^{* *}$ & \\
\hline
\end{tabular}


Tabela 3 - Valores da análise de desdobramentos das interações significativas para os sintomas de danos visuais da lagarta-do-cartucho em híbridos de milho pulverizados ou não. Pindorama, SP, 2007/2008.

\begin{tabular}{|c|c|c|c|}
\hline \multirow{3}{*}{ Híbridos (H) } & \multicolumn{2}{|c|}{ Notas de sintomas aos $40 \mathrm{DAE}^{1}$} & \multirow{3}{*}{ Teste F } \\
\hline & \multicolumn{2}{|c|}{ Inseticida (I) } & \\
\hline & Não Pulverizado & Pulverizado & \\
\hline DKB 330 & $3,08 \mathrm{~A} \quad \mathrm{a}$ & $2,74 \quad$ B $\quad$ a & $0,72^{\mathrm{ns}}$ \\
\hline AG 9010 & $2,31 \mathrm{~A} \quad \mathrm{a}$ & $1,86 \mathrm{AB}$ a & $1,23^{\text {ns }}$ \\
\hline DKB 390 & $2,53 \mathrm{~A} \quad \mathrm{~b}$ & $1,26 \mathrm{~A} \quad \mathrm{a}$ & $9,66^{* *}$ \\
\hline DKB 350 & $2,64 \mathrm{~A} \quad \mathrm{~b}$ & $1,24 \mathrm{~A}$ & $11,78^{* *}$ \\
\hline AG 7000 & $3,31 \mathrm{~A} \quad \mathrm{~b}$ & 1,34 A & 23,50 ** \\
\hline Teste F & $2,06^{\mathrm{ns}}$ & $4,94^{* *}$ & \\
\hline \multirow{2}{*}{ Híbridos (H) } & \multicolumn{2}{|c|}{ Notas de sintomas aos $70 \mathrm{DAE}^{1}$} & \multirow{2}{*}{ Teste F } \\
\hline & Não Pulverizado & Pulverizado & \\
\hline DKB 330 & $4,39 \mathrm{AB} \quad \mathrm{a}$ & $3,81 \quad \mathrm{C} \quad \mathrm{a}$ & $2,62^{\mathrm{ns}}$ \\
\hline AG 9010 & $4,29 \mathrm{AB} \quad \mathrm{b}$ & 2,83 BC a & $16,57^{* *}$ \\
\hline DKB 390 & $3,47 \mathrm{~A} \quad \mathrm{~b}$ & $1,88 \mathrm{AB} \quad \mathrm{a}$ & $19,52^{* *}$ \\
\hline DKB 350 & $3,81 \mathrm{AB} \quad \mathrm{b}$ & $1,51 \mathrm{~A}$ & $41,20^{* *}$ \\
\hline AG 7000 & 4,79 В $\quad$ b & $2,31 \mathrm{AB}$ & $47,69^{* *}$ \\
\hline Teste F & $4,15^{\star *}$ & $12,52^{* *}$ & \\
\hline \multirow{2}{*}{ Híbridos $(\mathrm{H})$} & \multicolumn{2}{|c|}{ Notas de sintomas aos $80 \mathrm{DAE}^{1}$} & \multirow{2}{*}{ Teste F } \\
\hline & Não Pulverizado & Pulverizado & \\
\hline DKB 330 & $4,38 \quad \mathrm{BC}$ a & $3,83 \quad$ C a & $1,92^{\mathrm{ns}}$ \\
\hline AG 9010 & $3,69 \mathrm{AB} \quad \mathrm{a}$ & 2,59 В & $7,76^{* *}$ \\
\hline DKB 390 & $2,74 \mathrm{~A}$ & $2,14 \mathrm{AB} \quad \mathrm{a}$ & $2,38^{\text {ns }}$ \\
\hline DKB 350 & $3,56 \mathrm{AB}$ & $1,04 \mathrm{~A}$ & $40,95^{\star *}$ \\
\hline AG 7000 & 5,33 C a & 2,93 BC a & $37,56^{* *}$ \\
\hline Teste F & $12,22 * *$ & $13,68^{* *}$ & \\
\hline
\end{tabular}

Já as interações entre híbrido e pulverizações foram significativas aos 40, 70 e 80 DAE (Tabela 1). Nas parcelas em que não ocorreu a pulverização com inseticidas, o híbrido que apresentou a maior nota foi AG 7000, principalmente aos 70 e 80 DAE, enquanto que o híbrido com a menor nota de sintoma foi DKB 390 (Tabela 3). Nas parcelas em que ocorreu a pulverização esperava-se que as diferenças não ocorressem ou se mantivessem como as parcelas sem pulverização, mas de forma menos intensa. No entanto, os híbridos responderam de formas diferentes à pulverização, na qual o híbrido mais atacado foi DKB330 (nota 3,89) e o menos atacado DKB350 $(1,04)$, conforme Tabela 3. Além disso, alguns híbridos não responderam às pulverizações, como DKB 330 (70 e 80 DAE) e DKB 390 (80 DAE) (Tabela 3).

Com relação à interação entre a transgenia e as pulverizações com inseticidas observou-se que em todas as avaliações tanto os híbridos convencionais, quanto os transgênicos, foram menos atacados quando receberam as pulverizações, com exceção da avaliação aos 40 DAE (Tabela 4). Nota-se que, apesar das notas dos sintomas visuais serem menores nos híbridos transgênicos, as pulverizações com inseti- cidas ainda proporcionaram alguma redução nos sintomas (Tabela 4).

Quando se analisaram os danos ocasionados pela lagartadocartucho, considerando os cinco híbridos em conjunto e como tratamentos a pulverização ou não e a transgenia ou não, notou-se que os materiais $B t$, pulverizados ou não, são menos atacados. Os materiais não $B t$ pulverizados apresentaram danos intermediários e os materiais não $B$ tnão pulverizados apresentaram as piores notas de sintomas (Fig. 1). Estes mesmos resultados também foram observados para o híbrido AG9010.

Para os híbridos DKB330 eDKB390 e seus respectivos materiais BtDKB330 YeDKB390Y, verificou-se que os materiais $B t$ foram os menos atacados e que as pulverizações nos materiais convencionais não reduziram significativamente as notas de sintomas em relação aos não pulverizados (Fig. 1).

No entanto, alguns híbridos apresentaram resultados diferentes dos observados anteriormente. Para os híbridos DKB 350/DKB350 Y e AG7000/ AG7000 $Y$, observou-se que os materiais convencionais destes híbridos quando pulverizados não diferiram significativamente dos materiais $B t$ não pulverizados com 
relação às notas de sintomas de ataque da lagarta (Fig. 1) nos levando a crer que, com relação aos danos ocasionados pela lagarta-do-cartucho, alguns híbridos $B t$ apresentam a mesma eficiência de controle que híbridos convencionais pulverizados com inseticida. Ou ainda, mesmo para materiais $B t$, em situações de alta infestação da lagarta é necessária a pulverização com inseticidas para diminuir a população da praga. WAQUIL et al. (2002) verificaram interações entre eventos e genótipos, na qual uma mesma toxina expressa em híbridos diferentes produziu resultados significativamente diferentes quanto à sobrevivência e desenvolvimento larval. LOURENÇão et al. (2009) também verificaram diferenças significativas quanto aos danos ocasionados por S. frugiperda entre os híbridos $B t$, inclusive com a presença de lagartas de $3^{\circ}$ estádio se alimentando em plantas de alguns desses híbridos.
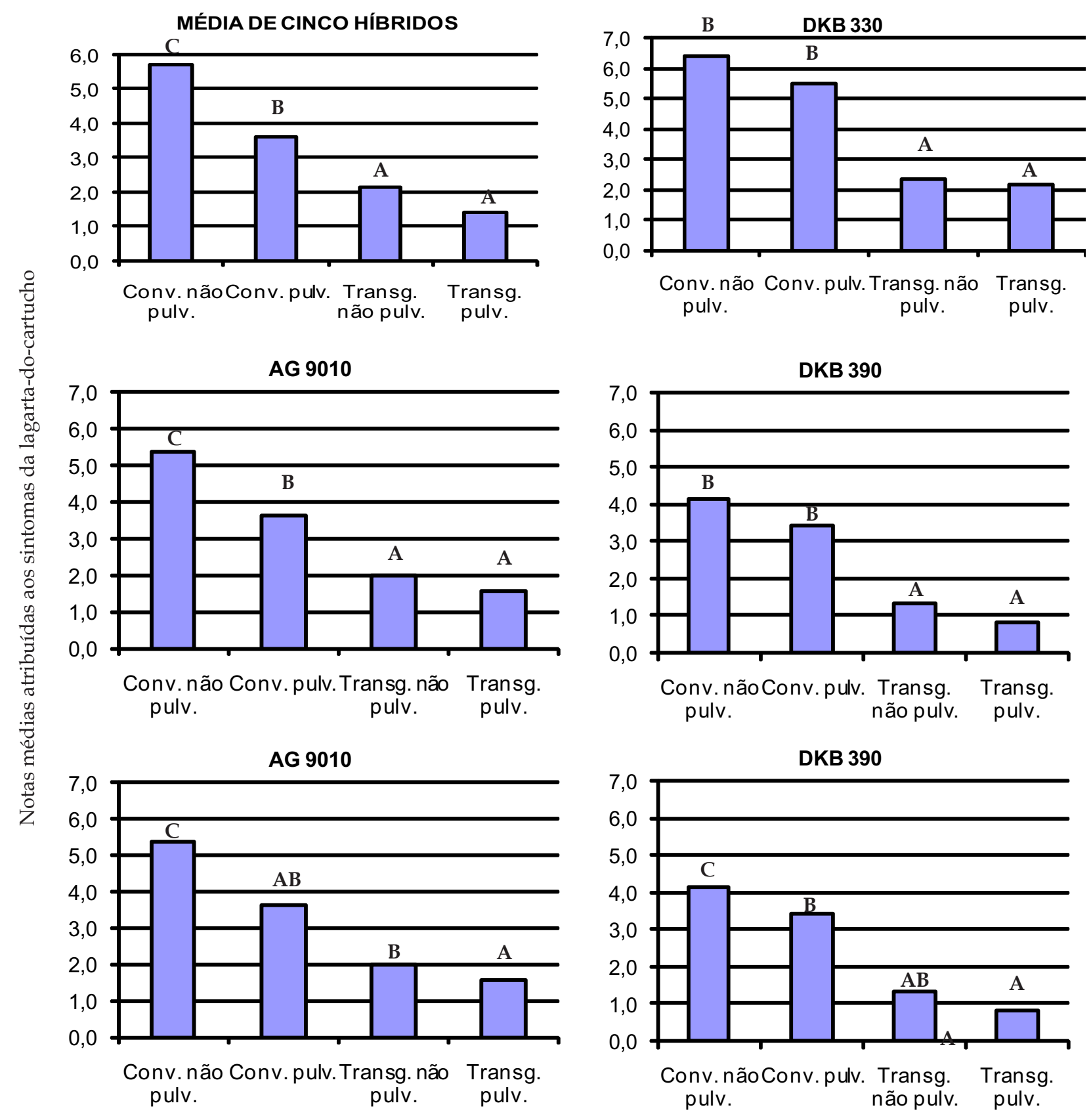

Híbridos de milho

Fig. 1 - Notas atribuídas aos sintomas de ataque da lagarta-do-cartucho nas plantas de diferentes híbridos de milho convencionais e transgênicos submetidos ou não ao controle químico, na fase de pré-pendoamento do milho. Pindorama, SP, 2008. 
Tabela 4 - Valores da análise de desdobramentos das interações significativas para os sintomas de danos da lagarta-docartucho em híbridos de milho convencionais e transgênicos (Bt) submetidos ou não ao controle químico. Pindorama, SP, 2008.

\begin{tabular}{|c|c|c|c|}
\hline & \multicolumn{2}{|c|}{ Notas de sintomas aos $40 \mathrm{DAE}^{1}$} & \multirow{3}{*}{ Teste F } \\
\hline & \multicolumn{2}{|c|}{ Inseticida (I) } & \\
\hline Transgenia $(\mathrm{T})$ & Não Pulverizado & Pulverizado & \\
\hline Convencional & $4,27 \quad \mathrm{~B} \mathrm{~b}$ & $2,25 \mathrm{~B} \mathrm{a}$ & $61,70 * *$ \\
\hline Transgênico $(B t)$ & $1,28 \mathrm{~A} \quad \mathrm{a}$ & $1,13 \mathrm{~A}$ a & $0,34^{\mathrm{ns}}$ \\
\hline \multirow[t]{2}{*}{ Teste F } & 135,30 ** & $19,01^{* *}$ & \\
\hline & \multicolumn{2}{|c|}{ Notas de sintomas aos $50 \mathrm{DAE}^{1}$} & \\
\hline Transgenia $(\mathrm{T})$ & Não Pulverizado & Pulverizado & leste F \\
\hline Convencional & $5,76 \mathrm{~B} \mathrm{~b}$ & $2,71 \quad \mathrm{~B} \mathrm{a}$ & $130,96^{* *}$ \\
\hline Transgênico $(B t)$ & $2,14 \mathrm{~A} \quad \mathrm{a}$ & $0,81 \mathrm{~A} \quad \mathrm{a}$ & $24,82^{* *}$ \\
\hline \multirow[t]{2}{*}{ Teste F } & $184,64^{* *}$ & $50,79 * *$ & \\
\hline & \multicolumn{2}{|c|}{ Notas de sintomas aos $60 \mathrm{DAE}^{1}$} & \\
\hline Transgenia $(\mathrm{T})$ & Não Pulverizado & Pulverizado & Teste F \\
\hline Convencional & 6,61 B b & $2,72 \mathrm{~B} \mathrm{a}$ & $253,39 * *$ \\
\hline Transgênico $(B t)$ & $2,46 \mathrm{~A} \quad \mathrm{a}$ & $0,91 \mathrm{~A}$ a & $40,23^{* *}$ \\
\hline \multirow[t]{2}{*}{ Teste F } & $289,44^{* *}$ & $55,31^{* *}$ & \\
\hline & \multicolumn{2}{|c|}{ Notas de sintomas aos $70 \mathrm{DAE}^{1}$} & \\
\hline Transgenia $(\mathrm{T})$ & Não Pulverizado & Pulverizado & leste F \\
\hline Convencional & $6,13 \mathrm{~B} \mathrm{~b}$ & $3,61 \mathrm{~B} \mathrm{a}$ & $123,33^{* *}$ \\
\hline Transgênico $(B t)$ & $2,18 \mathrm{~A} \quad \mathrm{a}$ & $1,33 \mathrm{~A} \quad \mathrm{a}$ & $13,83^{* *}$ \\
\hline \multirow[t]{2}{*}{ Teste F } & $302,17^{* *}$ & $100,02^{* *}$ & \\
\hline & \multicolumn{2}{|c|}{ Notas de sintomas aos $80 \mathrm{DAE}^{1}$} & Toste F \\
\hline Transgenia $(\mathrm{T})$ & Não Pulverizado & Pulverizado & Ieste $\mathrm{F}$ \\
\hline Convencional & $5,71 \mathrm{~B} \mathrm{~b}$ & $3,61 \quad \mathrm{~B} \mathrm{a}$ & $71,87^{* *}$ \\
\hline Transgênico $(B t)$ & $2,17 \mathrm{~A} \quad \mathrm{a}$ & $1,41 \mathrm{~A}$ a & $9,37^{* *}$ \\
\hline
\end{tabular}

${ }^{1}$ Médias seguidas de mesma letra minúscula na linha e maiúscula na coluna não diferem entre si pelo teste de Tukey a $5 \%$ de probabilidade.

Com relação aos danos ocasionados pelas lagartas na espiga, não se observaram interações significativas entre os fatores avaliados (Tabela 5). Para os danos da lagarta-do-cartucho na espiga, o híbrido menos infestado foi DKB 390 com 3,75\%, e para os danos na ponta da espiga, os materiais com menor infestação foram DKB 350 e 390, com 29,38 e 31,88\% das espigas atacadas (Tabela 5).

A transgenia também proporcionou menor percentagem de espigas danificadas. Já a pulverização não apresentou controle (Tabela 5), o que era de se esperar uma vez que as pulverizações foram realizadas somente enquanto foi possível a entrada do pulverizador tratorizado na área, o que aconteceu até os 55 DAE. DuARTE et al. (2007) observaram que para os híbridos de milho não $B t$ a percentagem de espigas com danos da lagarta da espiga foi de $35,4 \%$, enquanto que nos híbridos $B t$ não foram observadas espigas com danos.

Com relação aos danos ocasionados por $D$. saccharalis nos colmos das plantas, também não foram verificadas interações significativas entre os fatores (Tabela 5). Os híbridos avaliados também não diferiram. Já a transgenia proporcionou menor percentagem de plantas atacadas e menores tamanhos das galerias. O mesmo resultado foi observado para as pulverizações com inseticidas. DuARTE et al. (2007) verificaram que os híbridos Bt apresentaram número de furos nos colmos ocasionados pela broca igual a 0,06 , enquanto que nos híbridos não $B t$, o número médio foi de 3,76, demonstrando uma alta eficiência no controle desta praga.

Segundo CALvin et al. (1988), as larvas de D. saccharalis ao se alimentarem danificam os tecidos de condução da planta de milho, interferindo particularmente com as etapas reprodutivas, com a circulação de nutrientes, o movimento de água e a produção e translocação de fotossintéticos (ou fotossintatos) para a espiga primária. Além disso, especula-se que os danos ocasionados pela broca mais próximos à espiga estariam relacionados diretamente com a produtividade em consequência de que os danos próximos à espiga interfeririam na translocação de nutrientes elaborados pela planta, que seriam carreados para uma maior produção de folhas, em detrimento da produção de grãos, em comparação com os ataques verificados nos entrenós mais distantes da espiga (CruZ, 2007). 
Tabela 5 - Percentagem de espigas atacadas por lagartas e danos ocasionados por D. saccharalis nas plantas de diferentes híbridos de milho convencionais e transgênicos $(B t)$ submetidos ou não à pulverizações com inseticidas na safrinha. Pindorama, SP. 2008.

\begin{tabular}{|c|c|c|c|c|}
\hline \multirow{2}{*}{ Híbridos (H) } & \multicolumn{2}{|c|}{$\%$ de espigas danificadas } & \multicolumn{2}{|c|}{ Danos da broca-da-cana-de-açúcar } \\
\hline & Ponta da espiga & Ponta da espiga & $\%$ de plantas brocadas & Tamanho da galeria $(\mathrm{cm})$ \\
\hline AG 7000 & $62,50 \quad \mathrm{~B}$ & $17,50 \quad \mathrm{~B}$ & $10,63 \mathrm{~A}$ & $2,47 \mathrm{~A}$ \\
\hline AG 9010 & $50,00 \quad B$ & $18,13 \quad \mathrm{~B}$ & $3,50 \mathrm{~A}$ & $0,78 \mathrm{~A}$ \\
\hline DKB 330 & $48,75 \quad B$ & $13,13 \quad B$ & $7,50 \mathrm{~A}$ & $3,16 \mathrm{~A}$ \\
\hline DKB 390 & $31,88 \mathrm{~A}$ & $3,75 \mathrm{~A}$ & $5,63 \mathrm{~A}$ & $1,66 \mathrm{~A}$ \\
\hline DKB 350 & $29,38 \mathrm{~A}$ & $6,25 \mathrm{AB}$ & $5,63 \mathrm{~A}$ & $1,31 \mathrm{~A}$ \\
\hline Teste F & $13,13^{* *}$ & $5,19 * *$ & $1,25^{\mathrm{ns}}$ & $1,54^{\mathrm{ns}}$ \\
\hline \multicolumn{5}{|l|}{ Transgenia $(\mathrm{T})$} \\
\hline Convencional & $67,75 \quad \mathrm{~B}$ & $15,25 \quad \mathrm{~B}$ & $10,50 \quad \mathrm{~B}$ & $3,20 \quad B$ \\
\hline Transgênico $(B t)$ & $21,25 \mathrm{~A}$ & $8,25 \mathrm{~A}$ & $2,75 \mathrm{~A}$ & $0,55 \mathrm{~A}$ \\
\hline Teste F & $156,76^{* *}$ & $8,70^{* *}$ & $15,40^{* *}$ & $17,25^{* *}$ \\
\hline \multicolumn{5}{|l|}{ Inseticida (I) } \\
\hline Não Pulverizado & $45,00 \mathrm{~A}$ & $10,00 \mathrm{~A}$ & $9,50 \quad \mathrm{~B}$ & $2,58 \quad \mathrm{~B}$ \\
\hline Pulverizado & $44,00 \mathrm{~A}$ & $13,50 \mathrm{~A}$ & $3,75 \mathrm{~A}$ & $1,18 \mathrm{~A}$ \\
\hline Teste F & $0,24^{\mathrm{ns}}$ & $2,43^{\mathrm{ns}}$ & $7,35^{*}$ & $4,36^{*}$ \\
\hline \multicolumn{5}{|l|}{ Interação } \\
\hline $\mathrm{F}(\mathrm{H} \times \mathrm{T})$ & $0,64^{\mathrm{ns}}$ & $1,20^{\mathrm{ns}}$ & $0,52^{\text {ns }}$ & $1,87^{\mathrm{ns}}$ \\
\hline $\mathrm{F}(\mathrm{H} \times \mathrm{I})$ & $1,62^{\mathrm{ns}}$ & $0,73^{\text {ns }}$ & $0,64^{\mathrm{ns}}$ & $0,91^{\mathrm{ns}}$ \\
\hline $\mathrm{F}(\mathrm{T} \times \mathrm{I})$ & $0,27^{\mathrm{ns}}$ & $0,22^{\mathrm{ns}}$ & $3,55^{\mathrm{ns}}$ & $1,67^{\mathrm{ns}}$ \\
\hline $\mathrm{F}(\mathrm{H} \times \mathrm{T} \times \mathrm{I})$ & $0,64^{\mathrm{ns}}$ & $1,20^{\mathrm{ns}}$ & $0,79^{\text {ns }}$ & $0,92^{\mathrm{ns}}$ \\
\hline CV (\%) & 23,88 & 13,55 & 38,80 & 19,73 \\
\hline
\end{tabular}

${ }^{1}$ Médias seguidas de mesma letra na coluna não diferem significativamente entre si pelo teste de Tukey a 5\% de proba-

\section{CONCLUSÕES}

Os híbridos avaliados possuem comportamentos naturalmente diferentes em relação ao ataque das pragas.

A transgenia com tecnologia YieldGard proporciona redução nos danos visuais ocasionados pelas pragas, embora apresente desempenho diferente entre os híbridos.

As pulverizações com inseticidas apresentam eficiência diferentena redução dos danos ocasionados pela lagarta-do-cartucho, entre os híbridos avaliados, e não controlam os danos decorrentes das lagartas na espiga quando realizadas somente até os 55 DAE.

\section{AGRADECIMENTO}

Os autores agradecem ao Engenheiro Agrônomo Cezário Aparecido Doná, da Monsanto do Brasil, pelo fornecimento das sementes e apoio no desenvolvimento do trabalho, e ao Dr. João Francisco dos Santos pelo auxílio nas análises estatísticas.

\section{REFERÊNCIAS}

ARMSTRONG, C.L.; PARKER, G.B.; PERSHING, J.C.; BROWN, S.M.; SANDERS, P.R.; DUNCAN, D.R.; STONE, T.; DEAN, D.A.; DEBOER, D.L.; HART, J.;
HOWE, A.R.; MORRISH, F.M.; PAJEAU, M.E.; PETERSEN, W.L.; REICH, B.J.; RODRIGUEZ, R.; SANTINO, C.G.; SATO, S.J.; SCHULER, W.; SIMS, S.R.; STEHLING, S.; TAROCHIONE, L.J.; FROMM, M.E. Field evaluation of European corn borer control in progeny of 173 transgenic corn events expressing an insecticidal protein from Bacillus thuringiensis. Crop Science, v.35, p.550-557, 1995.

BARRY, B.D.; DARRAH, L.L.; HUCKLA, D.L.; ANTONIO, A.Q.; SMITH, G.S.; O'DAY, M.H. Performance of transgenic corn hybrids in Missouri for insect control and yield. Journal of Economic Entomology, v.93, n.3, p.991-999, 2000.

BUNTIN, G.D.; LEE, D.; WILSON, D.M.; MCPHERSON, R.M. Evaluation of YieldGard transgenic resistance for control of fall armyworm and corn earworm (Lepidoptera: Noctuidade) on corn. Florida Entomologist, v.84, n.1, p. 37-42, 2001.

CARNEVALLI, P.C.; FLORCOVSKI, J.L. Efeito de diferentes fontes de nitrogênio em milho (Zea mays L.) sobre Spodoptera frugiperda (J. E. Smith, 1797). Ecossistema, v.20, p.41-49, 1995.

CARVALHO, R.P.L. Danos, flutuação populacional, controle e comportamento de Spodoptera frugiperda (Smith 1797) e susceptibilidade de diferentes genótipos de milho em condições de campo. 1970. $170 \mathrm{f}$. Tese (Doutorado) - Escola Superior de Agricultura Luiz de Queiroz - Universidade de São Paulo, Piracicaba, 1970. 
CONAB. Companhia Nacional de Abastecimento. (Brasil) Acompanhamento da safra brasileira: grãos. 2009. Disponível em: <http://www.conab.gov.br/conabweb/download/ safra/12graos_08.09.pdf>. Acesso em: 15 set. 2009.

CRUZ, I. A broca da cana-de-açúcar, Diatraea saccharalis, em milho, no Brasil. Sete Lagoas: Embrapa-CNPMS, 2007. 12p. (Circular Técnica 90).

CRUZ, I.; TURPIN, F.T. Efeito da Spodoptera frugiperda em diferentes estádios de crescimento da cultura de milho. Pesquisa Agropecuária Brasileira, v.17, n.3, p.35560, 1982.

CRUZ, I.; BIANCO, R. Manejo de pragas na cultura de milho safrinha. In: SEMINÁRIO NACIONAL DE MILHO SAFRINHA, 6., 2001, Londrina. Anais. Londrina: Iapar, 2001. p.79-112.

CRUZ, I.; FIGUEIREDO, M.L.C.; OLIVEIRA, A.C.; VASCONCELOS, C.A. Damage of Spodoptera frugiperda (Smith) in different maize genotypes cultivated in soil under three levels of aluminum saturation. International Journal of Pest Management, v.45, p.293-296, 1999.

DAVIS, F.M.; NG, S.S.; WILLIAMS, W.P. Visual rating scales for screening whorl-stage corn for resistance to fall armyworm. Mississipi: Agricultural and Forest Experiment Station, 1992. 9p. (Technical Bulletin, 186).

DUARTE, J.M.; GOMES, M.S.; SALDANHA, L.A.; ARGENTA, G.; RAMBO, L. Eficácia de híbridos de milho Bt11 no controle de lepidópteros-praga em condições de campo sob infestação natural. 2007. Disponível em: <http:/ / www.syngenta.com.br/cs/Resumo \%20 expandido $\% 20$ milho\%20Bt11.pdf>. Acesso em: 10 fev. 2009.

FERNANDES, O.D.; PARRA, J.R.P.; NETO, A.F.; PÍCOLI, R.; BORGATO, A.F.; DEMÉTRIO, C.G.B. Efeito do milho geneticamente modificado MON 810 sobre a lagarta-do-cartucho Spodoptera frugiperda (J. E. Smith, 1797) (Lepidoptera: Noctuidae). Revista Brasileira de Milho e Sorgo, v.2, n.2, p.25-35, 2003.

GALLO, D.; NAKANO, O.; SILVEIRA NETO, S.; CARVALHO, R.P.L.; BAPTISTA, G.C.; BERTI FILHO, E.; PARRA, J.R.P.; ZUCHHI, R.A.; ALVES, S.B.; VENDRAMIM, J.D.; MARCHINI, L.C.; LOPES, J.R.S.; OMOTO, C. Entomologia Agrícola. Piracicaba: FEALQ, 2002. 920p.

GASSEN, D.N. Novos problemas com pragas na cultura do milho safrinha. In: SEMINÁRIO SOBRE A CULTURA DO MILHO SAFRINHA, 5., 1999, Barretos. Anais. Campinas: IAC, 1999. p.51-76.

GILL, S.S. Mechanism of action of Bacillus thuringiensis toxins. Memórias do Instituto Oswaldo Cruz, v.90, n.1, p. 69-74, 1995.
GILL, S.S.; COWLES, E.A.; PIETRANTONIO, P.V. The mode of action of Bacillus thuringiensis endotoxins. Annual Review of Entomology, v.37, p.615-636, 1992.

HUANG, F.; BUSCHMAN, L.L.; HIGGINS, R.A.; LI, H. Survival of Kansas dipel-resistant European corn borer (Lepidoptera: Crambidae) on Bt and non-Bt corn hybrids. Journal of Economic Entomology, v.95, n.3, p.614621, 2002.

JAMES, C. Global review of commercialized transgenic crops: 2000. Ithaca: 2000. 110p. (ISAAA Briefs, 23).

LYNCH, R.E.; WISEMAN, B.R.; SUMNER, H.R. PLAISTED, D.; WARNICK, D. Management of corn earworm and fall armyworm (Lepdoptera: Noctuidae) injury on a sweet corn hybrid expressing a Cry1A(b) gene. Journal of Economic Entomology, v.92, n.5, p.12171222, 1999.

LOURENÇÃO, A.L.F.; BARROS, R.; MELO, E.P. de Milho Bt: uso correto da tecnologia. In: Tecnologia e produção: milho safrinha e culturas de inverno. Maracajú: Fundação MS, 2009. p.79-89.

MEYERS, H.B., JOHNSON, D.R.; SINGER, T.L.; PAGE, L.M. Survival of Helicoverpa zea Boddie on Bollgard ${ }^{\circledR}$ cotton. In: BELTWIDE COTTON CONFERENCE, 1997, New Orleans. Proceedings. Memphis: National Cotton Council, 1997. v.2, p.1269-1271.

PENCOE, N.L.; MARTIN, P.M. Development and reproduction of fall armyworm on several wild grasses. Environmental Entomology, v.10, n.6, p.999-1002, 1981.

PICANÇO, M.C.; SEMEÃO, A.A.; GALVÃO, J.C.C; SILVA, E.M.; BARROS, E.C. Fatores de perdas em cultivares de milho safrinha. Acta Scientiarum. Agronomy, v.26, n.2, p.161-167, 2004.

PIETRANTONIO; P.V.; FEDERICI, B.A.; GILL, S.S. Interaction of Bacillus thuringiensis endotoxins with the insect midgut epithelium. In: THOMPSON, S.N.; FEDERICI, B.A. (Ed.) Parasites and pathogens of insects. New York: Academic Press, 1993. v.2, cap.3, p.55-79.

WAQUIL, J.M.; VILELLA, F.M.F.; FOSTER, J.E. Resistência do milho (Zea mays L.) transgênico (Bt.) à lagarta-do-cartucho, Spodoptera frugiperda (Smith) (Lepidoptera: Noctuidae). Revista Brasileira de Milho e Sorgo, v.1, n.3, p.1-11, 2002.

WILLIAMS, W.P.; SAGERS, J.B.; HANTEN, J.A.; DAVIS, F.M.; BUCKLEY, P.M. Transgenic corn evaluated for resistance to fall armyworm and southwestern corn borer. Crop Science, v.37, p.957-962, 1997.

Recebido em 2/12/09

Aceito em 29/11/10 